\title{
UM ESTUDO DO NICHO DE DESENVOLVIMENTO DE UM GRUPO DE CRIANÇAS EM UMA COMUNIDADE RURAL
}

\author{
Sanya Franco Ruela* \\ Maria Lucia Seidl de Moura ${ }^{\#}$
}

\begin{abstract}
RESUMO. Este trabalho adota uma perspectiva de desenvolvimento situado no contexto, empregando a noção de nicho de desenvolvimento, definido a partir de três subsistemas: ambiente físico e social, práticas de cuidado e psicologia dos cuidadores. Seu objetivo foi investigar as idéias e práticas de um grupo de mães e o ambiente físico e social que elas propiciam a seus filhos, em uma comunidade rural do Estado do Rio de Janeiro. Seis mães foram observadas com seus bebês em suas casas, e preencheram um inventário específico. A idade das mães variou de 19 a 32 anos e seu nível educacional de fundamental a médio. Os bebês tinham entre 1 e 21 meses. Em geral, os resultados sugerem, como previsto pelo modelo, uma interação entre os componentes do nicho. Explicitam, também, concepções de maternidade e desenvolvimento reveladas pelos membros dessa comunidade, e permitem considerações sobre o nicho de desenvolvimento das crianças estudadas.
\end{abstract}

Palavras-chave: nicho de desenvolvimento, ambiente rural, desenvolvimento infantil.

\section{A STUDY OF DEVELOPMENTAL NICHE OF A GROUP OF CHILDREN IN A RURAL COMMUNITY}

\begin{abstract}
This study adopts a perspective of development as contextually situated, employing the notion of developmental niche that is composed of three sub-systems: social and physical environment, care practices, and the psychology of the caregivers. The aim of the study was to investigate the ideas and practices of the mothers, and the physical and social environment they offer to their children in a rural community of the State of Rio de Janeiro. Six mothers were observed at home with their children and filled a specific inventory. Mothers age varied from 19 to 32 years, and their educational level ranged from elementary to high school. Babies had from 1 month to 21 months. In general, the results suggest, as predicted by the model, an interaction between those components. They also indicate conceptions of maternity and development shared by members of this community, and allow considerations about the developmental niche of the children studied.
\end{abstract}

Key words: Developmental niche, rural environment, infant development.

\section{UN ESTUDIO DEL LUGAR DEL DESARROLLO DE NIÑOS EN UNA COMUNIDAD RURAL}

RESUMEN. Este trabajo adopta una perspectiva del desarrollo situado en el contexto, empleando la noción del lugar de desarrollo que se compone a partir de tres subsistemas: ambiente social y físico, prácticas de cuidado, y la psicología de los cuidadores. El objetivo fue el de investigar las ideas y las prácticas de un grupo de madres, y el ambiente físico y social que ofrecen a sus niños en una comunidad rural del estado de Río de Janeiro. Seis madres fueron observadas con sus bebés en sus casas y llenaron un inventario específico. La edad de las madres variaba de 19 a 32 años, y su nivel educacional de la primaria a la secundaria. Los bebés tenían entre 1 y 21 meses. Por lo general los resultados sugieren, según lo previsto por el modelo, una interacción entre esos componentes. También indican conceptos de maternidad y desarrollo revelados por los miembros de esa comunidad y permiten consideraciones sobre el lugar de desarrollo de los niños estudiados.

Palabras-clave: lugar de desarrollo, ambiente rural, desarrollo infantil.

* Mestre pelo Programa de Pós-Graduação em Psicologia Social da Universidade do Estado do Rio de Janeiro.

\# Pós-doutora. Professora Titular do Instituto de Psicologia da Universidade do Estado do Rio de Janeiro. 
$\mathrm{O}$ interesse por compreender o desenvolvimento humano como um fenômeno que ocorre em um contexto que é, ao mesmo tempo, físico, social, histórico e cultural tem proporcionado intensos debates e relevantes produções empíricas e teóricas sobre o assunto (Cole, 1998; Harkness \& Super, 1996; Keller \& cols., 2004; Rabinovich, 1998; Valsiner, 1997). Com isso, tem-se observado na psicologia do desenvolvimento uma tendência a adotar uma perspectiva sociocultural (Rogoff \& Chavajay, 1995).

De maneira geral, segundo os princípios da abordagem sociocultural, o desenvolvimento humano dá-se através de trocas interacionais com parceiros, mediadas por instrumentos, em um contexto ao mesmo tempo social, histórico e cultural (Rogoff \& Chavajay, 1995). As crianças vivem desde antes do nascimento em ambientes culturalmente organizados, e são recebidas pelos adultos com crenças, expectativas representações e atividades mediadas pelos instrumentos desta cultura. Os bebês, ao nascer, como diz Cole (1998), são objetos da interpretação culturalmente condicionada dos adultos. Eles vêm "banhados nos conceitos da cultura sobre bebês, da mesma forma que vêm banhados no líquido amniótico" (p. 184).

Assim, levando em conta a importância do contexto para compreensão do desenvolvimento, estudos têm sido feitos em diferentes culturas (p. ex. Quênia X E.U.A.; Harkness \& Super, 1992) e em diferentes grupos culturais (p. ex. sociedades tradicionais X industriais, em Small, 1999). No entanto, apesar do significativo volume de pesquisas produzido nessa área, observa-se que a maioria das investigações em psicologia do desenvolvimento focaliza grupos urbanos de sociedades industriais ou pós-industriais. Com isso, os ambientes não ocidentais e, principalmente, rurais são raramente privilegiados.

Segundo Tomlinson e Swartz (2003), nascem a cada ano mais ou menos 135 milhões de bebês por ano no mundo, sendo que aproximadamente $90 \%$ deles em países em desenvolvimento. No entanto, segundo esses autores, 95\% das pesquisas sobre infância desde 1996 é de autoria de pesquisadores norte americanos, europeus, australianos e da Nova Zelândia, e, pode-se acrescentar, esses estudos são, principalmente, em ambientes urbanos. Além disso, observa-se na literatura que estudos interculturais, quando são feitos, muitas vezes comparam dois grupos de mães ou de crianças, por exemplo, de um ou dois países de primeiro mundo (da Europa ou Estados Unidos), com grupos de outro país, asiático, latino americano ou africano. Fala-se de crianças americanas e africanas, por exemplo, quando sabemos como são diversas internamente essas culturas.

Um dos problemas que essas tendências acarretam, e que é apontado por Cole (1998), é a construção de um padrão de normalidade para o desenvolvimento infantil, para a criação de filhos e para o que os pais pensam e como agem. Esse padrão é muito influenciado por resultados de pesquisas ocidentais, urbanas, realizadas com grupos de pessoas de um bom nível de escolaridade, que não traduzem a complexidade e variedade das populações humanas. A partir disso, muitas conseqüências sérias podem ocorrer, como, por exemplo, ter uma ciência do desenvolvimento humano, que se mostra limitada e viesada, generalizar indevidamente conclusões de estudos empíricos em populações específicas, e desenvolver e aplicar programas de intervenção a partir dessas conclusões, sem se preocupar com sua possível inadequação.

Em relação a ambientes não-urbanos e urbanos, estudos atuais que vêm sendo realizados por Keller e colaboradores (Keller \& cols., 2004; Keller, Borke, Yovsi, Lohaus \& Jensen, 2005) a partir de seu modelo de trajetórias de socialização (Keller, 2002) têm demonstrado que os diferentes ambientes apresentam características próprias em termos de contextos de socialização. Para esta autora haveria dois modos de investimento parental típicos, um ocidental e outro não ocidental. No primeiro, caracteristicamente não ocidental e não urbano, o cuidado físico inclui a amamentação durante dois a quatro anos, o bebê é carregado durante seus primeiros anos mais do que $50 \%$ do tempo, o contato corporal se dá durante o dia e a noite (nas costas, na frente ou no quadril da mãe), as crianças dormem com os adultos e os cuidados extras são oferecidos à criança por outros parentes e irmãos. Paralelamente, neste modo de investimento parental, o cuidado emocional apóia uma longa simbiose com a mãe e se caracteriza por longos períodos de cuidados que ocorrem conjuntamente a outras atividades do adulto, e contato corporal e comunicação longos e prolongados. Em contraste, no modo ocidental (sobretudo no meio urbano), o cuidado físico é caracterizado por um período de amamentação em média bem mais curto (de um a três meses), por reduzidos períodos de carregar o bebê, principalmente em resposta a seu choro, e por pouco contato corporal. Os cuidados extras oferecidos são, em geral, pagos (por exemplo, babás, creches). Quanto ao cuidado emocional, ele promove a independência cedo e envolve períodos curtos de cuidados exclusivos e períodos também curtos de episódios face-a-face. Assim, estudos que focalizem 
os diferentes ambientes de socialização são necessários e importantes.

De qualquer forma, esforços recentes têm sido feitos com a intenção não só de considerar o contexto como parte indispensável do processo de desenvolvimento humano como também de definir contextos e como eles podem ser estudados. Na literatura, tem recebido destaque o modelo de nicho de desenvolvimento de Harkness e Super (1994). Estes autores propõem que, para se estudar o desenvolvimento infantil, é importante caracterizar um sistema que inclui como subsistemas o ambiente físico e social da criança e as crenças e práticas de seus cuidadores. Eles consideram a moradia da família como o centro da vida humana inicial, e o desenvolvimento da criança como tendo uma relação dinâmica com o ambiente físico e social, com as práticas de cuidados infantis culturalmente reguladas e com a psicologia dos seus cuidadores. De acordo com esses autores, estes subsistemas organizam e norteiam as experiências de desenvolvimento da criança, fornecendo as informações a partir das quais a criança constrói sua cultura particular, dentro da cultura da sua sociedade.

\section{O NICHO DE DESENVOLVIMENTO: O AMBIENTE FÍSICO E SOCIAL NO QUAL A CRIANÇA VIVE, OS COSTUMES E PRÁTICAS DE CUIDADOS PARENTAIS E A PSICOLOGIA DOS CUIDADORES}

Em estudos com famílias de uma comunidade rural do Quênia e da América do Norte, Harkness e Super (1992) descrevem como os três componentes do nicho de desenvolvimento se imbricam, dando destaque especial ao papel das etnoteorias parentais e à sua origem sociocultural para o comportamento e desenvolvimento da criança.

Esses autores (Harkness \& Super, 1992) entendem que as crenças parentais dão direção ao comportamento dos pais e revelam como eles interpretam a realidade e a internalizam. Para estes autores, essas crenças podem ser vislumbradas nos diferentes ambientes físicos e sociais que os pais oferecem para seus filhos, nas metas de socialização e desenvolvimento, e nos cuidados dirigidos às crianças. Acrescentam, ainda, que estas crenças são frutos tanto das experiências de indivíduos como pais, quanto da experiência cultural acumulada durante as gerações sobre o que são e como devem agir nesses papéis. Assim, o conjunto de crenças construídas conjuntamente por membros de uma sociedade influencia o cuidado da criança e pode resultar em diferenças no desenvolvimento.
Sobre este aspecto, é interessante mencionar uma reportagem, de 1996, do jornal "The New York Times", citada por Small (1999), que relaciona o estilo e a prática parental e as diversas culturas no Brooklyn, em Nova Iorque. Como relatado, alguns pais e avós imigrantes desta localidade têm enfrentado problemas na orientação e educação de suas crianças devido a sua herança cultural. Em países como Nigéria e Caribe, segundo o artigo, é comum os pais aplicarem punição física como uma prática de criação e educação de filhos. No entanto, nos Estados Unidos, a punição física tem outro significado e os filhos que sofrem agressão corporal de seus pais têm o direito de solicitar proteção do Estado. $\mathrm{O}$ confronto entre diferentes crenças e estilos parentais tem originado, assim, situações complexas e delicadas para serem resolvidas. Os pais oriundos da Nigéria e do Caribe, por exemplo, aprenderam em suas comunidades de origem que a punição física seria um modo correto de educar filhos. Em contrapartida, seus filhos, nascidos e criados nos Estados Unidos, reivindicam ser tratados de acordo com os costumes norte-americanos. Assim, quando ocorre a punição física, muitos dos filhos desses imigrantes ligam para a polícia, denunciam seus pais e pedem proteção.

Segundo Small (1999), no tipo de situação relatada, é muito delicado afirmar o que é certo e o que é errado. Cada grupo cultural acredita que suas crenças, metas e estilos parentais estão corretos já que foram apreendidos em seu ambiente sociocultural. Esse exemplo ilustra o fato de que as diversas culturas existentes imprimem suas características em muitos aspectos da parentalidade, como por exemplo, sobre o que os pais pensam a respeito de cuidados parentais e sobre o que desejam para o futuro de seus filhos, revelando-se, assim, como um importante fenômeno a ser estudado de modo consistente.

Em relação às práticas parentais, Harkness e Super (1992) encontraram em seus estudos evidências de como o comportamento de quem cuida do bebê pode afetar a saúde e o desenvolvimento dele. Em Kokwet, uma localidade rural do Quênia, durante o dia, os bebês são presos junto ao corpo de suas mães, que os carregam por onde forem. À noite, eles dormem em contato com elas (co-sleeping) e, quando mais velhos, em contato com outras crianças de suas famílias. Esta prática de dormir ao lado da mãe nos primeiros meses de vida favorece a amamentação, que ocorre à vontade. Contudo, parece que esta prática influencia o padrão de sono noturno dos bebês. Normalmente os bebês ocidentais, por volta de seis 
semanas de vida, começam a se aproximar de um padrão de sono dia/noite, o que não é comum entre os bebês de Kokwet. Além disso, segundo Harkness e Super (1992), muitas linhas de evidências experimentais sugerem que uma conseqüência de um extenso contato físico é a promoção do crescimento e desenvolvimento normal, incluindo tamanho do corpo, atenção e emergência de competências neuromusculares.

No Brasil, as práticas de cuidados infantis valorizadas por mães também têm sido alvo de investigações. Rabinovich (1998), objetivando comparar as práticas de aleitamento entre famílias de um bairro paulistano e famílias de uma localidade rural piauiense, como contexto de desenvolvimento, observou diferenças significativas quanto ao tempo de amamentação dos bebês, nestes dois ambientes. No Piauí, as mães contavam com apoio de familiares como tios e avós nos cuidados dirigidos ao bebê e o tempo de aleitamento ultrapassava os seis meses, na maioria dos casos. Em São Paulo, as mães eram freqüentemente apontadas como as únicas responsáveis pelos cuidados com seus filhos e, o aleitamento dos bebês tendia a ser suspenso antes dos três meses. Deste modo, parece que o funcionamento interdependente da vida familiar (rede de apoio social), no Piauí, contribui de alguma forma para o maior tempo de aleitamento, em relação aos bebês de São Paulo.

Observa-se, assim, que a expressão das crenças e dos valores culturais tem uma importância central na estruturação do ambiente físico e social e nos cuidados que serão oferecidos as crianças em diferentes contextos culturais, tendo estes três componentes do nicho um impacto imediato sobre o desenvolvimento delas.

Diante dos dados empíricos e teóricos apresentados, compreende-se que o modelo de nicho de desenvolvimento pode constituir-se em uma orientação válida para se estudar a parentalidade e o desenvolvimento infantil em diferentes contextos, como ambientes rurais, onde há ainda no Brasil uma carência de estudos. Seus três componentes (o ambiente físico e social da criança, os costumes e práticas e a psicologia dos cuidadores) são importantes indicadores de como se desenrolam estes fenômenos na medida que consideram a família como o primeiro núcleo social do bebê e atribuem a ela a função de capacitá-lo a viver dentro de sua cultura, sendo o ambiente doméstico um local adequado para o cuidado dele.

Assim, tomando como base principalmente o pensamento destes autores, e considerando a carência de estudos de desenvolvimento e parentalidade no ambiente rural, em geral e no Brasil, foi realizado este estudo exploratório. Seu objetivo foi investigar o ambiente físico e social de crianças da comunidade de Ribeirão de São Joaquim, analisar algumas idéias, concepções e práticas de suas mães e o que elas desejam para o futuro de seus filhos, de forma a buscar caracterizar um nicho de desenvolvimento rural brasileiro.

Nesse sentido, considera-se que, mesmo exploratório, este estudo pode contribuir para o conhecimento de contextos não urbanos de desenvolvimento, fornecendo evidências, permitindo algumas inferências e dando bases para a formulação de hipóteses e realização de futuros estudos, de maior amplitude.

\section{MÉTODO}

\section{$O$ ambiente de estudo}

Ribeirão de São Joaquim localiza-se na região sulfluminense do Rio de Janeiro e é distrito do município de Quatis. Sua população, atualmente, é de aproximadamente 500 habitantes, que vivem no vilarejo (arraial) e nas fazendas e sítios (IBGE, 2000).

Os adultos deste Distrito têm seus papéis sociais bem definidos. Os homens trabalham em alguma atividade externa ao lar, como por exemplo: como pecuaristas, funcionários da Prefeitura Municipal, autônomos, entre outros. À mulher cabe o cuidado com a casa e com os filhos e, se o marido for pecuarista e/ou agricultor, ajudá-lo em algumas atividades como as colheitas e fabricação de queijos. Existem, ainda, algumas mulheres que têm trabalho remunerado, geralmente como empregadas domésticas, babás e professoras. O rendimento nominal médio mensal das famílias é de, aproximadamente, R\$ 340,51 (IBGE, 2000). As pessoas mais velhas ajudam seus familiares e o distrito no cuidado com a igreja, com a programação das festividades locais, pequenos afazeres domésticos, etc.. As famílias, há trinta anos atrás eram grandes, com mais de cinco filhos, principalmente as que viviam em fazendas e sítios. Atualmente elas mantêm uma média de três filhos (IBGE, 2000).

\section{Participantes}

Participaram desta pesquisa seis díades mãe-bebê, em que a idade das mães variou de 19 a 32 anos, e o nível de escolaridade de ensino fundamental ao ensino médio. Todas as mães estavam vivendo com o pai do bebê, no momento deste estudo. Os bebês tinham 
idades variando de 1 mês a 1 ano e 9 meses. Eles são cuidados principalmente por suas mães e dois dos bebês ficam durante um período do dia com uma babá.

As famílias das díades estudadas apresentam a seguinte composição: (1) Díade 01 é composta por quatro membros: mãe, pai, irmã do bebê e o bebê. $\mathrm{O}$ pai tem 38 anos estudou até a $4^{\mathrm{a}}$ série do ensino fundamental e trabalha como pedreiro. A mãe tem 28 anos e tem o ensino fundamental incompleto e o bebê tem 1 ano e 9 meses. A irmã do bebê tem 8 anos e cursa a $2^{a}$ série, na escola do Distrito. (2) Díade 02: mãe, pai, irmão do bebê e o bebê. O pai do bebê tem 37 anos, sua escolaridade é de ensino médio incompleto e sua profissão é pecuarista. A mãe do bebê tem 32 anos, ensino médio completo e trabalha como auxiliar administrativo. Por este motivo, o bebê, que tem 1 ano e 9 meses, é cuidado em uma parte do dia por uma babá. O irmão do bebê cursa a $6^{\mathrm{a}}$ série, na escola do Distrito e tem 12 anos. (3) Díade 3: pai, mãe, bebê e duas irmãs mais velhas do bebê. O pai do bebê tem 38 anos, estudou até a $4^{\mathrm{a}}$ série do ensino fundamental e trabalha como guarda municipal em Quatis. A mãe do bebê tem 29 anos, estudou até a $8^{\text {a }}$ série do ensino médio e trabalha como telefonista. Este bebê também é cuidado por uma babá em um período do dia. A irmã mais velha do bebê tem 10 anos e cursa a $5^{\mathrm{a}}$ série e a mais nova tem 6 anos e cursa o CA. O bebê tem 7 meses. (4) Díade 04: pai, mãe, irmão do bebê e o bebê. O pai tem 38 anos, sua escolaridade é de ensino fundamental incompleto e ele trabalha como encarregado da manutenção da estrada que liga o Distrito a Quatis. A mãe tem 25 anos e ensino fundamental incompleto. $\mathrm{O}$ bebê tem 11 meses. $\mathrm{O}$ irmão do bebê tem 8 anos e cursa a $2^{\mathrm{a}}$ série na escola do Distrito. (5) Díade 5: mãe, pai, dois irmãos do bebê e o bebê. O pai do bebê tem 27 anos, estudou até a $3^{\text {a }}$ série e trabalha como empregado de um sítio. A mãe tem 19 anos e estudou até a $4^{\mathrm{a}}$ série. O bebê tem 7 meses e seus irmãos têm 2 e 3 anos. (6) Díade 6: pai, mãe e o bebê. $\mathrm{O}$ pai tem 34 anos, ensino fundamental incompleto e trabalha como pedreiro. A mãe tem 19 anos e ensino médio completo e não tem trabalho externo ao lar.

\section{Instrumentos}

Os instrumentos utilizados incluíram a observação naturalística que teve como meta investigar o comportamento da díade mãe-bebê em sua residência no contexto rural; o diário de campo que incluiu a descrição das atividades realizadas durante a observação e buscou captar a rotina da mãe com seu filho (a); e o Inventário do Nicho de Desenvolvimento para registro de algumas informações das díades que participaram desse estudo.

O diário de campo foi estruturado segundo dois tópicos principais. O primeiro envolveu a descrição de algumas práticas e rotinas diárias das díades durante a observação como alimentação/ refeição, cuidados higiênicos, cuidados com a saúde, descanso/sono do bebê, brincadeira e atividades durante o período de vigília tanto com a mãe e outras pessoas como sozinho e, por último, falas de pessoas dirigidas ao bebê. $\mathrm{O}$ segundo tópico incluiu a descrição do ambiente físico e social da díade, como por exemplo, os objetos que pertenciam ao bebê e como eles estavam dispostos dentro da casa da família dele.

O Inventário do Nicho de Desenvolvimento é constituído de questões abertas e fechadas relativas às seguintes categorias: identificação, ambiente físico, ambiente social, sobre você mãe e sobre você e seu filho.

A primeira categoria contém itens de identificação da díade, como por exemplo, o nome da mãe e do bebê e a idade deles. A categoria ambiente físico diz respeito à moradia e se e como a mãe limita este espaço para a sua criança. A terceira categoria refere-se ao ambiente social que é oferecido para a criança, com questões sobre pessoas que convivem com ela, e o que fazem juntas, além de informações acerca da rede de apoio familiar e de cuidados não materno que a criança recebe. A categoria sobre você mãe foi elaborada a partir de adaptações do questionário metas de socialização de Harwood e colaboradores (Leyendecker, Harwood, Lamb \& Sholmerich, 2002) e acrescida de outras questões com o objetivo de se averiguar algumas idéias, da participante, sobre como é ser mãe para ela e sobre o desenvolvimento infantil. A última categoria, sobre você e seu filho, colhe informações de algumas atividades que realizam no dia-a-dia e sobre o(s) ambiente(s) que ela costuma freqüentar com seu(s) filho(s).

\section{Procedimentos}

As famílias foram contatadas previamente consentiram em participar do estudo. Um fator que contribuiu para essa aceitação foi a primeira autora, que colheu os dados em campo, ter família na localidade e ser conhecida de todos os participantes.

Buscando uma descrição rica das características do ambiente físico e social da díade e das atividades que realizam em seu dia-a-dia, foram feitas observações na casa das díades, durante dois dias, em turnos diferentes, cada turno com duração de 6 horas, aproximadamente. 
Durante e imediatamente ao final das observações, foram feitos os registros destas em um diário de campo.

Durante a estadia do observador na casa das famílias, as mães juntamente com o observador, preencheram o Inventário do Nicho de Desenvolvimento, sem tempo pré-determinado para terminá-lo. As dúvidas foram esclarecidas à medida que apareciam, de forma imparcial.

Apesar do foco do estudo ser a díade mãe-bebê, não foi solicitado que os outros membros da família ficassem fora da casa, durante a realização da observação. Deste modo, foi possível que mantivessem suas atividades cotidianas, mesmo se isso envolvesse um ou os dois membros da dupla. Além disso, a família foi solicitada a manter sua rotina diária e a ignorar, na medida do possível, a presença do observador.

\section{Análise de dados}

As análises foram feitas segundo os dados obtidos no Inventário do Nicho de Desenvolvimento, e a partir do diário de campo, articulados segundo os objetivos deste estudo. Assim, os registros das observações foram cotejados com a análise de conteúdo dos inventários, na tentativa de se compreender melhor a dinâmica das famílias participantes, principalmente das díades, e fazer algumas inferências sobre o nicho de desenvolvimento delas, no contexto rural.

Para melhor acompanhamento e compreensão dos dados, os componentes do Nicho de Desenvolvimento também orientaram a apresentação e discussão dos resultados a seguir.

\section{RESULTADOS E DISCUSSÃO}

\section{Ambiente físico e social}

Em relação ao ambiente físico, observou-se que as moradias eram simples, compostas por um, dois ou três quartos, uma sala, uma ou duas varandas, cozinha, e banheiro. No quintal de quatro casas havia uma horta com hortaliças e legumes e jardins com flores e árvores frutíferas, como goiabeiras. $\mathrm{Na}$ casa de todas as famílias havia luz elétrica, e a água e o esgoto eram canalizados. Em nenhuma casa havia muros de tijolos, em duas havia somente um cercado lateral de bambu, e em uma outra, cerca viva (arbustos).

Foi observado, também, que a maioria das casas estava asseada e arrumada, e a maior responsável por esta atividade era a mãe. Em quase todos os cômodos das casas havia objetos do bebê. As famílias com melhores condições financeiras dispunham de mais espaço e de mais móveis e objetos. Em quatro residências notou-se a presença de berços e em cinco, de banheirinhas. A maioria dos bebês freqüienta todos os cômodos, como afirmaram as mães (Inventário do Nicho de Desenvolvimento).

Este ambiente revelou-se também como um limitador ou facilitador das experiências desenvolvimentais dos bebês. A presença de cadeirinhas, mamadeiras, banheirinha, entre outros, indicam a atenção e conhecimento (crenças) dos pais sobre o desenvolvimento dos bebês e de suas necessidades e possibilidades de ação no mundo. Por outro lado, a presença de caixotes (objeto similar ao "cercadinho", de alguns contextos urbanos), em duas casas, revelou uma prática materna que os limitam em termos de espaço e descobertas em fases iniciais, quando o bebê ainda não alcançou uma relativa autonomia e independência motora (ele não anda, por exemplo). Nesta comunidade, muitos bebês permanecem boa parte do dia nos caixotes com alguns brinquedos enquanto suas mães realizam algumas tarefas domésticas,

A análise do ambiente social revelou que além de seu lar, os bebês freqüentam outros espaços como a pracinha, o campinho, o coreto, as casas e as ruas de Ribeirão de São Joaquim. Nestes espaços eles convivem com diferentes pessoas que não fazem parte de sua família nuclear, entre elas: as avós e os avôs, alguns tios, primos, e os amigos dos pais e irmãos dos bebês. Normalmente todos conversam com os bebês, brincam com eles e às vezes cuidam deles, como, por exemplo, dando banho e colocando-os para dormir. Apenas um bebê deste estudo convive no dia-a-dia, normalmente, só com sua família nuclear porque mora em um sítio afastado do arraial. Os bebês também convivem em grupo de outras pessoas, com uma freqüência menor, no qual podem ser incluídas quase todas as pessoas do distrito. Isto ocorre devido às relações de amizades e/ou familiar que os tornam muito próximos. Esta rotina propicia à criança interações com outros adultos e crianças, contribuindo para o seu desenvolvimento social, além de oferecer à mãe um recurso muito importante para o cuidado de seus filhos: uma rede de apoio.

Neste sentido, as avós maternas dos bebês foram apontadas pelas mães como pessoas prestativas e que as ajudaram, de forma relevante, a desempenhar seu papel de mãe e a cuidar de seus filhos. Esse resultado pode ser explicado pelo papel social atribuído à mulher na maternidade, difundido e compartilhado por diversas culturas no mundo. No contexto rural, onde as famílias são geralmente caracterizadas como patriarcais, às mulheres cabe o cuidado e educação da criança, 
cabendo também a ela auxiliar e transmitir seus conhecimentos sobre o papel materno para outras mulheres, principalmente para suas filhas. Por esse foco, seria esperado o resultado encontrado.

\section{Práticas parentais}

Foram considerados os episódios que envolviam a alimentação, o sono, os cuidados higiênicos e com a saúde do bebê, as brincadeiras e a fala de pessoas dirigidas a ele. Para o seu registro foi feita uma descrição geral da rotina diária das díades a partir dos relatos das mães e das observações feitas através de visitas domiciliares, como se segue no exemplo da díade 1:

\begin{abstract}
"Díade 01 (bebê com 1 ano e 9 meses e mãe com 28 anos): Manhã: Todos os dias quando acorda a mãe coloca o bebê para urinar e evacuar, no piniquinho dele no banheiro. Depois ela escova os dentes dele, lava suas mãos e rosto. Ás vezes, o bebê come algo de manhã, porque ele mamou muitas vezes durante a noite. Durante o período da manhã, segundo a mãe, o bebê gosta de brincar com sua irmã, primas e amigas e/ou ver televisão. A mãe realiza tarefas domésticas como lavar, cozinhar, etc. Tarde: Às 12:30 aproximadamente, o bebê almoça e toma banho. Quando está calor o bebê toma vários banhos por dia. A mãe sempre lembra que o bebê tem que tomar água, porque considera que ele não gosta muito. Nos intervalos destas atividades, o bebê é amamentado. A mãe continua fazendo tarefas domésticas. $\mathrm{O}$ bebê dorme normalmente, das 13:00 às 15:00. Ainda à tarde, quando os primos estão na casa da família ele brinca com eles, se não estiverem, mãe, bebê e a irmã dele se arrumam e vão para a casa da avó materna. Ficam lá até as 18:30. Eles também vão à casa do avô paterno. Noite: Ao retornar para sua casa, eles assistem TV (novelas e telejornais), esperam o pai do bebê voltar do trabalho (ele é pedreiro), tomam banho, jantam e vão dormir. Quando um primo ou amiguinho está na casa da família, o bebê e sua irmã trocam a televisão pela brincadeira". (Diário de Campo: díade 01)
\end{abstract}

As práticas de cuidado observadas com os diversos bebês mostraram um tipo de criação onde as mulheres (mãe, irmãs do bebê ou babás) são as principais responsáveis pelas crianças. Elas também são as responsáveis pelas tarefas domésticas, cabendo, em geral, ao homem o trabalho externo ao lar que garante ou complementa a renda familiar.
Além disso, foi possível observar que o cuidado era empreendido por mulheres diversas como avós maternas dos bebês, tias, irmãs, primas, babás e etc, que sempre estavam próximas a eles procurando interagir, geralmente, através de brincadeiras durante o banho e a alimentação, por exemplo. Em muitos casos, o cuidado era realizado de forma simultânea às outras tarefas ou ao cuidado dos outros filhos. Assim, o cuidado dirigido ao bebê revelou ser, nesta comunidade, um cuidado não-exclusivo, no qual é valorizado tanto o contato corporal, como a interação face-a-face, mediada pela fala e por objetos. Estas características também indicam o estabelecimento de vínculo afetivo desde cedo entre estas pessoas e o bebê.

Em relação ao sono foi observado que, em todos os casos, pais e bebês dormiam em um mesmo quarto, sendo que metade $(n=3)$ dormia na cama junto aos pais e a outra metade em seu próprio berço, ao lado da cama do casal. Contudo, quatro dos bebês possuíam berços, o que nos leva a concluir que a presença do berço nem sempre significava que o bebê dormia nele. As mães percebiam como positiva esta proximidade. Para elas, esta prática as auxiliava a atender prontamente qualquer necessidade do bebê, principalmente de alimentação.

Sobre este aspecto, apesar das mães atribuírem o fato dos bebês dormirem no mesmo quarto que os pais a necessidade de alimentação dos bebês, esta conduta é percebida pelas autoras como uma possibilidade de se fortalecer os laços afetivos e familiares, à medida que promove proximidade, cuidado e dedicação entre pais e filhos. Uma outra vantagem desta prática de dormirem juntos, pais e bebês, é facilitar o ajuste da regulação interna de mecanismos térmicos e respiratórios do bebê, ainda, imaturos, e mesmo para evitar a doença que acomete as crianças dormindo (Síndrome de Morte Infantil Súbita - SIDS; Morelli \& cols., 1992; Rabinovich, 1994). Para Rabinovich (1998), os resultados destes estudos fazem a ciência questionar a prática de utilização de berço muito comum nas comunidades americana e européia.

Os bebês que compõem as díades 01, 04, 05, e 06 são alimentados no seio, sendo que os bebês 01 e 05 não fazem alimentação exclusiva no seio materno. Eles e os bebês 02 e 03 fazem alimentação regular com café da manhã, almoço, lanche e jantar. A comida para os bebês mais novos (03 e 05) é feita de forma especial e separada da comida da família. A mãe do bebê 03 (7 meses) disse que parou de alimentar o bebê com leite materno por conta do trabalho (ela é telefonista). $\mathrm{O}$ mesmo afirmou a mãe do bebê 02 que trabalha na escola. Durante o intervalo das refeições principais, os 
bebês também comiam, por exemplo, bananas e biscoitos quando a mãe dava ou quando eles pediam.

\begin{abstract}
"Díade 03 (bebê com 7 meses e mãe com 29 anos): 13:10 a mãe terminou de preparar o almoço do bebê e colocou a comida no prato (vidro) com uma colher de alumínio. Ela foi até a sala, onde o bebê estava sentado dentro do seu carrinho. A mãe colocou uma fralda embaixo do pescoço dele (como babador) e começou a lhe dar o almoço, brincado de aviãozinho para ele abrir a boca. Ela falou: "Se não brincar não come, não é?". O bebê vocalizou e mexeu os membros. Ele terminou de almoçar às 13:25. A mãe deu um pouco de água para o bebê no copo de plástico dele". (Diário de Campo: díade 03)
\end{abstract}

Em relação às atividades predominantes dos bebês durante o tempo de observação, as brincadeiras se destacaram. Elas ocorreram, na maioria das vezes, acompanhadas por suas primas, amigas, babá, mãe, pai e irmãos e, geralmente, não eram os bebês que as propunham. Em quatro famílias, os brinquedos utilizados eram compartilhados entre o bebê e seu(s) irmão(s) e ficavam guardados em caixa próprias em um lugar de fácil acesso, dentro de casa. Entre eles estavam incluídos bonecas, fogãozinho, panelinhas, bolas, carrinhos, brinquedos de plástico que imitam personagens de desenho da televisão, etc. As brincadeiras observadas e elas ocorreram, na maioria das vezes, nos cômodos das casas. Apenas um bebê passava boa parte do dia brincando em um caixote (objeto semelhante ao cercadinho), mas ele não parecia gostar muito e, às vezes, chorava. Todos os episódios observados foram registrados no diário de campo, como no exemplo a seguir:

"Díade 02 (bebê com 1 ano e nove meses e mãe com 33 anos) 08:22 o bebê começou a brincar de fazer "comidinha" com a prima e com a irmã na sala, utilizando um conjunto de panelas, talheres, potes e um fogão (miniaturas). Os brinquedos eram de plástico. Em seguida, elas foram brincar na calçada. Elas recolhiam pétalas e folhas, pegavam areia do chão da rua e colocavam nas panelinhas, todas eram cozinheiras. Ás 08:30 outras duas amigas juntaram-se à brincadeira. $\mathrm{O}$ bebê segurou o fogãozinho para a irmã colocar as panelinhas com areia e flores, a comida foi servida nos potinhos e elas brincaram de "comer" àquela comida. Ás 08:32 a brincadeira terminou e eles foram para a sala ver TV" (Diário de Campo: díade 02)

De um modo geral, os episódios de atividade lúdica mostraram que as crianças brincam de modo diferente em idades diferentes e têm estilos próprios de brincar. Os bebês mais velhos tenderam a ter um maior período de brincadeiras, e eles também podiam escolher mais com o que brincar, pois já andavam. Os mais novos dispunham de um menor grau de autonomia e independência, sendo suas brincadeiras propostas, quase sempre, por outras pessoas mais velhas do seu meio social.

As brincadeiras em grupo que foram observadas envolveram mais a imitação de papéis sociais de adulto como brincar de casinha. O bebê do sexo masculino que participou da pesquisa brincou com seu irmão de carrinho e de luta entre os bonecos de plástico.

\section{Psicologia dos cuidadores}

Em relação às crenças, todas as mães deste estudo relatam que a maternidade é uma experiência de vida positiva e satisfatória. Quanto às metas que têm para seus filhos, predominou a de que eles se desenvolvam fisicamente e profissionalmente e se tornem pessoas boas, amigas e trabalhadoras. Observa-se que são metas mais voltadas para qualidades associadas com o desenvolvimento do potencial pessoal, físico e econômico, mas de forma que atenda às expectativas sociais do ambiente sociocultural onde vivem (ser trabalhador), tudo isso mediado pelo calor emocional com o outro (Harwood \& cols, 1996).

Crenças mais específicas apareceram refletidas nas falas das mães. Como por exemplo, relativas às diferenças de gênero. Nesse sentido, uma mãe afirmou achar que é mais fácil desacostumar um bebê do sexo masculino a usar fraldas porque ele tem pênis e, por isso, entende mais rápido que as meninas. Além disso, uma das mães vestiu uma camisa em seu bebê dizendo que não faz bem uma pessoa ficar sem camisa quando está trovejando. Uma crença compartilhada sobre a chuva com outras pessoas desse distrito.

Foram observadas, ainda, outras práticas que pareciam estar baseadas em conhecimentos populares locais, muito valorizados nesta comunidade. Por exemplo, durante a observação, uma mãe deu chá de erva-cidreira (capim-limão) para o bebê dizendo que era para ele se acalmar e outra esfregou alho na mão do bebê para aliviar a irritação provocada por uma picada de mutuca (um tipo de inseto comum nesta localidade).

O conhecimento das mães sobre o desenvolvimento humano foi verificado, de um modo geral, através da segunda questão do inventário do nicho de 
desenvolvimento. Para elas as crianças diferenciam-se de adultos, principalmente, porque elas dependem de cuidados e atenção para sobreviverem: "Um adulto é responsável, pode ficar sozinho e uma criança não" (mãe 01); "A criança é mais carente de cuidados" (mãe 02); “A criança não sabe fazer nada, tadinha!" (mãe 05), ou porque as crianças não têm algumas competências que os adultos têm: "Um adulto doente fala o que está sentindo, diferente de uma criança que não sabe falar. A minha filha é pequena e não alcança algumas coisas" (mãe 01); "Um bebê não fala, não anda" (mãe 03); “A criança não sabe o que ela faz, ela é inocente" (mãe 04). As mães também, apontaram como características das crianças: ser meiga e esperta (mãe 01), ser mais inocente e sincera (mãe 02) e tranqüila (mãe 03).

Assim, pensar no modo como as mães cuidam de seus bebês, ou no que acreditam como o modo adequado de cuidado com eles, implica também o modo segundo o qual as metas de socialização das mães para seus filhos, seus conhecimentos sobre o desenvolvimento infantil e outros aspectos relacionados ao tema se configuram e são co-construídos por elas, em relações com parceiros em seu meio sociocultural.

\section{CONSIDERAÇÕES FINAIS}

A proposta desse estudo foi de descrever e apontar aspectos do nicho de desenvolvimento de bebês que vivem em um ambiente rural. Desta forma, o estudo de alguns aspectos da maternidade e do desenvolvimento infantil, considerado como situado no contexto, garantiu uma ampla visão deste fenômeno e algumas possíveis implicações do meio rural nele.

Como se infere a partir dos resultados, o modo de vida familiar na comunidade de Ribeirão de São Joaquim pode ser caracterizado como compartilhado (com pais, irmãos, amigos, primos, avós, tios, babás, entre outros.), na medida que a criação dos filhos não é exclusiva da família nuclear do bebê (pai, mãe e irmãos). Esta característica parece ser culturalmente compartilhada pois aparece refletida nas falas das mães, em seus comportamentos e no ambiente físico e social que elas ofereceram a seus filhos. Como resultado para os bebês, este modo de vida familiar oferece a eles oportunidades de interações com adultos e crianças diversos, que convivem com ele diariamente ou não. Para autores da abordagem sociocultural (Rogoff \& Chavajay, 1995), estas interações promovem o desenvolvimento do bebê porque favorecem os contatos entre ele e pessoas mais experientes de seu contexto sociocultural. Desta forma, a rede familiar extensa, além de fornecer apoio à mãe, coloca o bebê em interações com outros membros de seu meio sociocultural, em diversas atividades como as de cuidados, de brincadeiras e de fala, por exemplo, que são muito importantes para o seu desenvolvimento e que contribuem para a sua inclusão como membro da cultura.

Assim, como se pode concluir a partir da análise geral dos dados e tal como proposto por Harkness e Super (1992), os três componentes do Nicho de Desenvolvimento (o ambiente físico e social e as crenças e práticas de seus cuidadores) se interinfluenciam formando o ecossistema de vida do bebê. Este modelo revela-se como um importante quadro teórico para o estudo do desenvolvimento infantil, considerando-o como situado em contextos, pois permite ao pesquisador observar como as características culturais do ambiente estudado imprimem suas marcas na parentalidade e no desenvolvimento infantil. Compreender isso parece ser fundamental quando se deseja ser um psicólogo do desenvolvimento ou quando se deseja trabalhar com famílias, seja qual for a profissão.

Acredita-se que a análise qualitativa dos dados e a metodologia empregada nesta investigação permitiram explorar algumas relações entre o contexto físico e cultural e as crenças e práticas de pessoas que convivem com os bebês, principalmente as mães, em Ribeirão de São Joaquim. Seus resultados, pela característica exploratória do estudo, apontam para a necessidade de novas pesquisas, que abordem aspectos da família, da parentalidade, das interações sociais e suas implicações para o desenvolvimento da criança, de forma mais específicas neste e em outros contextos. A partir deste trabalho, investigações mais amplas sobre o desenvolvimento e o ambiente sociocultural desta e de outras comunidades rurais, são desejadas e possíveis.

\section{REFERÊNCIAS}

Cole, M. (1998). Cultural psychology: A once and future discipline. Cambridge: The Belknap.

Harkness, S. \& Super, C. M. (1992). Parental ethnotheories in action. In I. E. Siegel, A.V. McGillicuddy-DeLisi \& J. J. Goodnow (Eds.). Parental belief systems: The psychological consequences for children (pp. 373-391). Hillsdale: Lawrence Erlbaum.

Harkness, S. \& Super, C. M. (1994). Developmental niche: A theoretical framework for analyzing the household production of health. Social Science and Medicine, 38(2), 219-226. 
Harkness, S. \& Super, C. M. (1996). Parents' cultural belief systems: Their origins expressions, and consequences. New York: The Guilford.

Harwood, R. L., Schoelmerich, A., Ventura-Cook, E., Schulze, P. A. (1996). Culture and class influences on Anglo and Puerto Rican mothers' beliefs regarding long-term socialization goals and child behavior. Child Development, 67, 2446-2461.

IBGE (2002). Censo demográfico -2000. Instituto Brasileiro de Geografia e Estatística. Disponível em: <http:// www.ibge.gov.br>. (Acesso em 13/01/2003).

Keller, H. (2002). Development as the interface between biology and culture: A conceptualization of early ontogenetic experiences. In H. Keller, Y. H. Poortinga \& A. Schölmerich (Eds.), Between culture an biology (pp. 215-240). Cambridge: University.

Keller, H., Borke, J., Yovsi, R., Kärtner, J., Jensen, H. \& Papaligoura, Z. (2004). Developmental consequences of early parenting experiences: Self-regulation and self-recognition in three cultural communities. Child Development, 75(6), 17451760.

Keller, H., Borke, J., Yovsi, R., Lohaus, A. \& Jensen, H. (2005). Cultural orientations and historical changes as predictions of parenting behavior. International Journal of Behavioral Development, 29(3), 229-237.

Leyendecker, B. Lamb, M. E. Harwood, R. L. \& Sholmerich, A. (2002). Mothers' socialization goals and evaluation of desirable and undesirable everyday situations in two diverse cultural groups. International Journal of Behavioral Development, 26, 248-258.

Morelli, G. A., Tronick, E. Z. \& Ivey, P. K. (1992). The Efe forager infant and toddler's pattern of social relationships multiple and simultaneous. Developmental Psychology, 28, 568-577.

Rabinovich, E. P. (1994). O modo de morar e a vida cotidiana como indicadores qualitativos do desenvolvimento infantil: um estudo de uma população de crianças de 0-3 anos na Zona Rural do Piauí, Brasil. Caderno de Desenvolvimento Infantil, 1, 47-59.

Rabinovich, E. P. (1998) Modos de morar no Brasil e contexto de desenvolvimento. Em Sociedade Brasileira de Psicologia (Orgs.), Anais da XXVIII Reunião Anual de Psicologia (pp. 74-80). Ribeirão Preto: SBP.

Rogoff, B. \& Chavajay, P. (1995). What's become of research on the cultural basis of cognitive development. American Psychologist, 50, 859-877.

Small, M. F. (1999). Our babies, ourselves: How biology and culture shape the way we parent. New York: Anchor Books.

Tomlinson, M. \& Swartz, L. (2003). Representing infancy across the world: Does Osama bin Laden love his children? Culture \& Psychology, 9, 487-497.

Valsiner, J. (1997, $2^{\text {nd }}$ Ed.). Culture and the development of children's actions. New York: John Wiley \& Sons.

Recebido em 10/11/2005 Aceito em 07/07/2006

Endereço para correspondência: Sanya Franco Ruela. Av. Portugal, 1552, ap. 33, Jardim Bela Vista, CEP 09041-320 Santo André-SP. E-mail: sanyafranco@bol.com.br 